\title{
Four years' monitoring of in vitro sensitivity and candidate molecular markers of resistance of Plasmodium falciparum to artesunate-mefloquine combination in the Thai-Myanmar border
}

\author{
Papichaya Phompradit ${ }^{1}$, Poonuch Muhamad ${ }^{2}$, Raewadee Wisedpanichkij ${ }^{3}$, Wanna Chaijaroenkul ${ }^{1}$ \\ and Kesara Na-Bangchang ${ }^{1 *}$
}

\begin{abstract}
Background: The decline in efficacy of artesunate (AS) and mefloquine (MQ) is now the major concern in areas along the Thai-Cambodian and Thai-Myanmar borders.

Methods: The correlation between polymorphisms of pfatp6, pfcrt, pfmdr 1 and pfmrp 1 genes and in vitro sensitivity of Plasmodium falciparum isolates to the artemisinin-based combination therapy (ACT) components $A S$ and $M Q$, including the previously used first-line anti-malarial drugs chloroquine (CQ) and quinine (QN) were investigated in a total of 119 P. falciparum isolates collected from patients with uncomplicated P. falciparum infection during 2006-2009.

Results: Reduced in vitro parasite sensitivity to AS [median ( $95 \%$ Cl) I $C_{50} 3.4(3.1-3.7) \mathrm{nM}$ ] was found in $42 \%$ of the isolates, whereas resistance to MQ [median (95\% Cl) IC 50 54.1 (46.8-61.4) nM] accounted for 58\% of the isolates. Amplification of pfmdr 1 gene was strongly associated with a decline in susceptibility of $P$. falciparum isolates to AS, MQ and QN. Significant difference in $\mathrm{I}_{50}$ values of $\mathrm{AS}, \mathrm{MQ}$ and $\mathrm{QN}$ was observed among isolates carrying one, two, three, and $\geq$ four gene copies [median (95\% Cl) AS IC 50 : 1.6 (1.3-1.9), 1.8 (1.1-2.5), 2.9 (2.1-3.7) and 3.1 (2.5-3.7) nM, respectively; MQ IC 50 : 19.2 (15.8-22.6), 37.8 (10.7-64.8), 55.3 (47.7-62.9) and 63.6 (49.2-78.0) nM, respectively; and QN IC 50 : 183.0 (139.9-226.4), 256.4 (83.7-249.1), 329.5 (206.6-425.5) and $420.0(475.2-475.6) \mathrm{nM}$, respectively]. The prevalence of isolates which were resistant to QN was reduced from 21.4\% during the period 2006-2007 to 6.3\% during the period 2008-2009. Pfmdr1 86Y was found to be associated with increased susceptibility of the parasite to MQ and QN. Pfmdr1 1034C was associated with decreased susceptibility to QN. Pfmrp1 191Y and 1390I were associated with increased susceptibility to CQ and QN, respectively.

Conclusion: High prevalence of CQ and MQ-resistant $P$. falciparum isolates was observed during the four-year observation period (2006-2009). AS sensitivity was declined, while QN sensitivity was improved. Pfmdr1 and pfmrp1 appear to be the key genes that modulate multidrug resistance in $P$. falciparum.
\end{abstract}

Keywords: Plasmodium falciparum, Artesunate, Mefloquine, pfmdr1, pfmrp1, pfatp6, pfcrt, Gene polymorphisms

\section{Background}

Southeast Asia, particularly the Thai-Cambodian border, is one of the malaria-endemic region where multidrugresistant Plasmodium falciparum malaria has been reported [1]. In the 1960s and 1970s, chloroquine (CQ) resistance spread throughout the region and subsequently,

\footnotetext{
* Correspondence: kesaratmu@yahoo.com

${ }^{1}$ Chulabhorn International College of Medicine, Thammasat University (Rangsit Campus), Patumthani 12121, Thailand

Full list of author information is available at the end of the article
}

in the 1980s, resistance to sulphadoxine and pyrimethamine was reported [2]. In 1984, mefloquine (MQ) was firstly introduced for clinical use as first-line treatment for uncomplicated multidrug-resistant $P$. falciparum malaria in Thailand, but MQ resistance was rapidly developed four years after its implementation. Following the decline in clinical efficacy of $\mathrm{MQ}$, the artemisininbased combination therapy (ACT) using the artesunatemefloquine combination was introduced as first-line reatment in 1994 [3]. Cure rate was improved to over $90 \%$ and 
the incidence of $P$. falciparum malaria was markedly reduced [4,5]. Artemisinin resistance however, initially occurred during 2006-2007 in areas along the ThaiCambodian border [6]. With regard to the Thai-Myanmar border, treatment failure following ACT has been increasing especially in Tak province [7]. Studies during 20082009 showed a marked decline in the 42-day cure rate from 99.2 to $72.58 \%[8,9]$. It is unclear whether artemisinin resistance has spread from the eastern to the western border of the country. Monitoring and identifying factors contributing to this low cure rate is necessary for the country's future perspective of malaria control policy. Applying genetic analysis as a tool for detecting the genetic change of malaria parasite genes that have been shown to link with the decline in efficacy of artesunate (AS) and MQ; i.e., pfmdr1 [10], pfatp6 [11] and pfmrp1 [12-14], in association with the in vitro sensitivity of the parasite to both combination partners, would help to detect early changes in P. falciparum sensitivity to this combination therapy.

In the present study, the association between the polymorphisms of pfatp6, pfcrt, pfmdr1, and pfmrp1 genes and in vitro sensitivity of $P$. falciparum isolates to AS, $\mathrm{MQ}$, as well as $\mathrm{CQ}$ and quinine $(\mathrm{QN})$ was investigated in $P$. falciparum isolates collected from the ThaiMyanmar border. In addition, the change in parasite genetic patterns and in vitro sensitivity over the period 2006-2009 was also examined.

\section{Methods}

\section{Blood samples}

A total of 130 P. falciparum isolates were collected from patients with uncomplicated $P$. falciparum infection prior to treatment with a three-day combination regimen $(25 \mathrm{mg} / \mathrm{kg}$ body weight MQ and $12 \mathrm{mg} / \mathrm{kg}$ body weight AS) for investigation of the polymorphisms of candidate molecular markers of anti-malarial drug resistance and in vitro parasite sensitivity. The study was conducted at Mae Tao clinic, Mae Sot District, Tak Province, Thailand during 2006-2009. Fifty-seven and 73 isolates were collected from patients during 20062007 and 2008-2009, respectively (Figure 1). The study protocol was approved by the Ethics Committee of the Ministry of Public Health of Thailand and written informed consents for study participations were obtained from all patients before study.

\section{Culture system and in vitro sensitivity assay}

All parasite isolates were adapted to continuous culture according to the method of [15] with modification. The laboratory-adapted 3D7 (CQ-sensitive) and K1 (CQ-resistant) $P$. falciparum were used as control parasite clones. Susceptibility of $P$. falciparum isolates to AS, $\mathrm{MQ}, \mathrm{CQ}$ and QN was investigated using SYBR Green I assay [16,17]. Highly synchronous ring stage parasites were used in each assay. An aliquot of parasite inoculum (50 $\mu \mathrm{l})$ with $2 \%$ parasitaemia and $1 \%$ haematocrit was added into each well of the 96-well microtitre plate. The plate was predosed with each anti-malarial drug at eight final concentrations as follows: AS: $0.39,0.78,1.56,3.13,6.25,12.5,25$, and $50 \mathrm{nM}$; MQ: 3.13, 6.25, 12.5, 25, 50, 100, 200, and 400 nM; CQ $(3.13,7.81,15.63,31.25,62.5,125,250$, and 500 $\mathrm{nM}$ ); and QN: 7.81, 15.63, 31.25, 62.5, 125, 250, 500, and 1,000 nM. Standard compounds of all anti-malarial drugs were purchased from Sigma-Aldrich Co (St Louis, MO, USA). All were stored at $-20^{\circ} \mathrm{C}$ as $10 \mathrm{mM}$ stock solutions in $50 \%$ ethanol. The experiments were repeated three times, triplicate for each experiment. $\mathrm{IC}_{50}$ value (concentration that inhibits parasite growth by $50 \%$ ) was used as an indicator for anti-malarial susceptibility and was determined from a log-dose response analysis using the Calcu$\operatorname{Syn}^{\mathrm{T}}{ }^{\mathrm{T}}$ computer program (Biosoft, Cambridge, UK). The criterion used for susceptibility of the parasite isolates to CQ was as follow: sensitive ( $\mathrm{S}$ : $\mathrm{IC}_{50}<25 \mathrm{nM}$ ), moderately resistant (MR: $25 \leq \mathrm{IC}_{50}<100 \mathrm{nM}$ ), and highly resistant (HR: $\mathrm{IC}_{50} \geq 100 \mathrm{nM}$ ). QN susceptibility was categorized into two levels, i.e., $\mathrm{S}\left(\mathrm{IC}_{50}<500 \mathrm{nM}\right.$ ), and resistant (R: $\mathrm{IC}_{50} \geq 500 \mathrm{nM}$ ). MQ susceptibility was categorized into two levels, i.e., "sensitive" ( $\mathrm{IC}_{50} \leq 24 \mathrm{nM}$ ) and "resistant" $\left(\mathrm{IC}_{50}>24 \mathrm{nM}\right)$. For AS, the susceptibility was classified as "sensitive" ( $\mathrm{IC}_{50} \leq$ upper limit of $95 \%$ CI of the median $\left.\mathrm{IC}_{50}\right)$ and "declined sensitivity" ( $\mathrm{IC}_{50}>$ upper limit of $95 \%$ confidence interval $(\mathrm{CI})$ of the median $\left.\mathrm{IC}_{50}\right)$ [18].

\section{Investigation of polymorphisms of pfcrt, pfmdr1, pfatp6, and pfmrp1 using PCR-RFLP}

Genomic DNA was extracted from all samples (cultureadapted P. falciparum; Figure 1) using chelex resin modified technique [19]. Prior to being used as a DNA template, concentration of the malaria genomic DNA was determined by spectrophotometry (Nanodrop ${ }^{\mathrm{TM}}$, Thermo fisher Scientific, Massachusetts, USA).

Previously published nested and PCR-RFLP methods were employed to detect the polymorphisms of $p f c r t$ gene at amino acid residues $76,220,271,326,356$, and 371 [20]; pfmdr1 gene at amino acid residues 86, 184, 1034, 1042, and 1246 [21,22]; pfatp6 gene at amino acid residues 37, 693, 769, 898 [23]; pfmrp1 gene at amino acid residues 191 and 437 [24]; and pfmrpl gene at amino acid residues 876, 1390 and 1466 [25].

\section{Detection of pfatp6 and pfmdr1 gene copy number by SYBR Green I real-time PCR}

Pfatp6 and pfmdr1 gene copy number in all samples (Figure 1) was determined by SYBR Green I real-time PCR (iCycler ${ }^{\text {tw }}$, Bio-Rad, California, USA) using the default thermocycler program: $10 \mathrm{~min}$ of pre-incubation at 


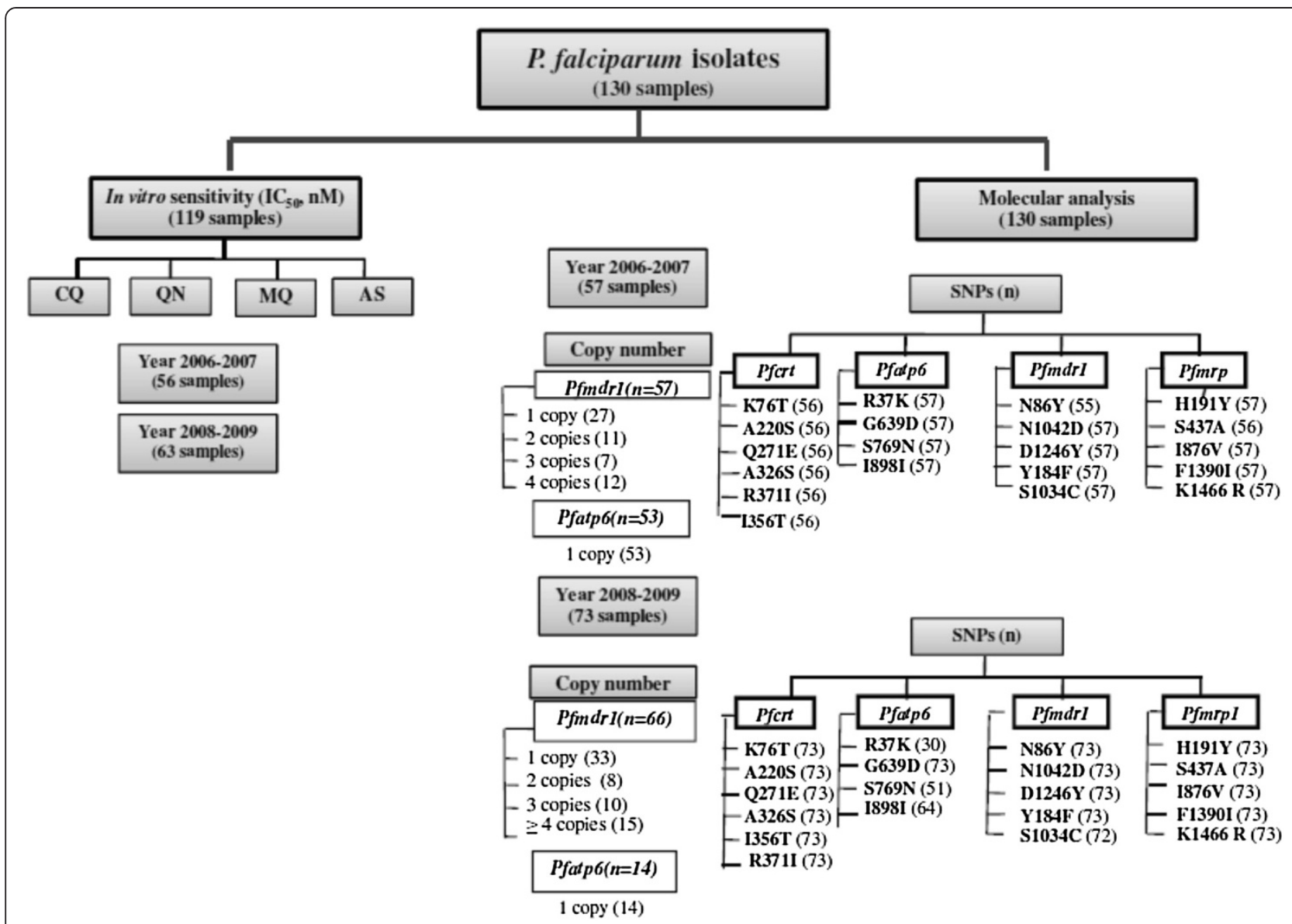

Figure 1 Frameworks of in vitro sensitivity and molecular analysis in Plasmodium falciparum isolates collected during 2006-2009. The number in parentheses signify the number of isolates included in the analysis.

$95^{\circ} \mathrm{C}$, followed by 40 cycles for $15 \mathrm{sec}$ at $95^{\circ} \mathrm{C}$ and $1 \mathrm{~min}$ at $60^{\circ} \mathrm{C}$. The oligonucleotide primers used were those previously designed by Ferreira et al. [26] with modification. Individual real-time PCR reaction was carried out in a $25 \mu \mathrm{l}$ reaction volume in a 96-well plate containing $2 \mu \mathrm{l}$ of DNA (50 ng), $1 \mu \mathrm{M}$ each of sense and antisense primer and $12.5 \mu \mathrm{l}$ of Platinum ${ }^{\text {tu }}$ PCR SuperMix (Invitrogen, California, USA).

The $2^{-\Delta \Delta \mathrm{Ct}}$ method of relative quantification was adapted to estimate copy number in $P$. falciparum genes. The genomic DNA extracted from $P$. falciparum 3D7 clone known to harbour a single copy of each gene was used as a calibrator, while Pf- $\beta$-actin 1 served as the house-keeping gene in all experiments. Dd2 genomic DNA carrying four copies of $p f m d r 1$ was used as a second calibrator. The threshold cycle $(\mathrm{Ct})$ was determined as the increase in reporter signal, which was first detected above baseline. Results were analysed by a comparative $\mathrm{Ct}$ method based on the assumption that the target (pfatp6 and pfmdr1) and reference (pf- $\beta$-actin 1) genes were amplified with the same efficiency within an appropriate range of DNA concentrations.
The $\Delta \Delta \mathrm{Ct}$ calculation for the relative quantification of target was as follow: $\Delta \Delta \mathrm{Ct}=(\mathrm{Ct}$, target gene $-\mathrm{Ct}$, Pf- $\beta$ actin 1$)_{\mathrm{x}}-(\mathrm{Ct} \text {, target gene }-\mathrm{Ct} \text {, Pf- } \beta \text {-actin } 1)_{\mathrm{y}}$, where $\mathrm{x}$ represents unknown sample and y represents $P$. falciparum 3D7 clone. Results for each sample was expressed as an $N$-fold change in $X$ target gene copies, normalized to Pf- $\beta$-actin- 1 relative to the copy number of the target gene in P. falciparum 3D7 clone, according to the following equation: amount of target $=2^{-\Delta \Delta \mathrm{Ct}}$. A minimum of two experiments were carried out for each gene and each sample. In each experiment, each individual sample was analysed in duplicate wells and the Ct of each well was recorded at the end of the reaction.

\section{Statistical analysis}

The association between in vitro sensitivity of $P$. falciparum isolates and polymorphisms of pfcrt, pfmdr1, pfmrp1, and pfatp6 was analysed using Chi-square and Mann-Whitney $U$ tests. Correlation between the two quantitative variables was evaluated using Spearman correlation test. The qualitative variables are summarized as proportions and percentages and the quantitative variables 
are summarized as median $(95 \% \mathrm{CI})$ values. Statistical significance level was set at $\alpha=0.05$ for all tests (SPSS version 15; SPSS, Chicago, Illinois, USA).

\section{Results}

In vitro sensitivity of Plasmodium falciparum isolates

In vitro sensitivity to $\mathrm{AS}, \mathrm{MQ}, \mathrm{CQ}$, and $\mathrm{QN}$ was successfully evaluated in a total of $119 \mathrm{P}$. falciparum isolates (Figure 1 and Table 1), 56 and 63 isolates collected during 2006-2007 and 2008-2009, respectively (Figure 1 and Table 2). Isolates with declined sensitivity to AS [median $(95 \% \mathrm{CI}) 3.4(3.1-3.7) \mathrm{nM}$ ] were observed in $42 \%$ (50 isolates). Fifty-eight per cent (69 isolates) were identified as MQ-resistant [median $(95 \% \mathrm{CI})=54.1(46.8-61.4)$ $\mathrm{nM}$ ]. Almost all (99.2\%, 118 isolates) were identified as moderately and highly CQ-resistant; only one $(0.8 \%)$ isolate was identified as CQ-sensitive $\left(\mathrm{IC}_{50}\right.$ values $\left.=9.6 \mathrm{nM}\right)$. About 13\% (16 isolates) were identified as QN-resistant [median $(95 \% \mathrm{CI})=648.9(621.2-676.5) \mathrm{nM}$ ]. A positive significant correlation was observed between the $\mathrm{IC}_{50}$ values of MQ and AS $(r=+0.662 ; p<0.001)$, MQ and QN $(r=+0.750 ; p<0.001)$, and AS and QN $(r=+0.625$; $p<0.001$ ) (Figure 2). There was no significant difference in the $\mathrm{IC}_{50}$ values of all drugs between isolates collected during the two periods. However, the prevalence of QNresistant isolates collected during 2008-2009 was significantly lower than during 2006-2007 ( $p=0.016)$.

\section{Candidate molecular markers of antimalarial drug resistance in Plasmodium falciparum isolates Pfatp6 mutation}

No mutation in pfatp6 at the target amino acid residues 37, 639 and 769 was found in any isolate $(0 / 87,0 / 130$, and

Table 1 In vitro sensitivity of Plasmodium falciparum isolates (represented by $I_{50}$ values) to chloroquine (CQ), quinine (QN), mefloquine (MQ), and artesunate (AS) and their sensitivity classification

\begin{tabular}{llll}
\hline Drug & Sensitivity classification & $\%(\mathbf{n})$ & $\mathbf{I C}_{50}, \mathbf{n M}$ \\
\hline AS & All & $100(119)$ & $2.0(1.7-2.3)$ \\
& Sensitive $\left(I C_{50} \leq 2.3 \mathrm{nM}\right)$ & $58.0(69)$ & $1.4(1.8-2.8)$ \\
& Declined sensitivity $\left(I C_{50}>2.3 \mathrm{nM}\right)$ & $42.0(50)$ & $3.4(3.1-3.7)$ \\
MQ & All & $100(119)$ & $30.1(21.8-33.3)$ \\
& Sensitive & $42.0(50)$ & $15.2(12.8-17.6)$ \\
& Resistant & $58.0(69)$ & $54.1(46.8-61.4)$ \\
CQ & All & $100(119)$ & $72.3(67.3-77.3)$ \\
& Sensitive & $0.8(1)$ & 9.6 \\
& Moderate resistant & $73.1(87)$ & $66.6(63.5-69.7)$ \\
& Highly resistant & $26.1(31)$ & $131.6(118.9-144.4)$ \\
QN & All & $100(119)$ & $231.7(192.2-271.2)$ \\
& Sensitive & $86.6(103)$ & $222.6(195.5-249.8)$ \\
& Resistant & $13.4(16)$ & $648.9(621.2-676.5)$ \\
\hline
\end{tabular}

Data presented as median $(95 \% \mathrm{Cl}$ ) and percentage (number).
$0 / 108$ isolate, respectively), whereas the mutation at 898 was detected in six out of $121(5.0 \%)$ isolates. Almost all isolates collected during 2006-2007 (100\%) and 2008-2009 (93.7\%) carried wild type pfatp6 at the target amino acid residues $37,639,769$, and 898 . There was a significant difference in the prevalence of isolates collected during 2006$2007(0 \%, 0 / 57)$ and $2008-2009(9.4 \%, 6 / 64)$ with regard to the mutation at the amino acid residue $898(p=0.018)$.

\section{Pfcrt mutation}

Almost all isolates carried mutated pfcrt gene. The prevalence of gene mutation at codons 76T, 220S, 271E, $326 \mathrm{~S}$, and 371I was $99.2 \%(128 / 129)$, while the mutation at the codon $356 \mathrm{~T}$ was $98.4 \%(127 / 129)$.

\section{Pfmdr1 mutation}

No mutation in pfmdr1 at the codons 1042D and 1246Y was observed (0/130 and 0/130) in any isolate collected during the two investigation periods. The prevalence of pfmdr 1 wild type at the target amino acid residue 86 was significantly higher in isolates collected during 2008-2009 $(100 \%, 73 / 73)$ compared with 2006-2007 (94.5\%, 52/55) $(p=0.043)$. The prevalence of $p f m d r 1$ wild type at the target amino acid residue 184 in isolates collected during 2006-2007 and 2008-2009 was 100\% (57/57) and 94.5\% (69/73), respectively. For the target amino acid residue 1034, mutant, heterozygous mutant and wild type isolates were detected in $15.8 \%$ (14/57), 56.6\% (34/57) and 24.6\% (9/57) of the isolates collected during 2006-2007, respectively. The prevalence of the mutant and heterozygous mutant at the same amino acid target was detected in 98.6 and $1.4 \%$ of the isolates collected during 2008-2009, respectively. No wild type isolate was found at this target amino acid. The prevalence of gene mutation at the amino acid residue 1034 was significantly higher in isolates collected between 2008-2009 compared with 2006-2007 $(p<0.001)$.

\section{Pfmrp1 mutation}

No mutation in pfimrp1 at the codon 1466R was observed $(0 / 130)$ in any isolate collected during both periods. The mutations at amino acid residues 191, 437, 876, and 1390 were detected in $86.9 \%$ (113/130), 89.1\% (115/129), 74.6\% (97/130) and 26.2\% (34/130), respectively. The prevalence of isolates with mutations at amino acid residues 191 and 437 collected during 2006-2007 vs 2008-2009 were $84.2 \%$ $(48 / 57)$ vs $89.0 \%(65 / 73)$ and $85.7 \%(48 / 56)$ vs $91.8 \%$ (68/ $73)$, respectively. The prevalence of isolates with mutations at amino acid residues $876(p<0.001)$ and $1390(p=$ $0.037)$ was significantly higher in $2008-2009$ (42.5\%, 31/ 73) compared with 2006-2007 (5.3\%, 3/57).

\section{Pfmdr1 copy number}

Isolates which carried one, two, three, four, five, six and eight gene copies were found in 48.8\% (60/123), 15.4\% 
Table 2 In vitro sensitivity of Plasmodium falciparum isolates collected during 2006-2007 and 2008-2009 to chloroquine (CQ), quinine (QN), mefloquine (MQ), and artesunate (AS) and their sensitivity classification

\begin{tabular}{|c|c|c|c|c|c|}
\hline \multirow[t]{2}{*}{ Drug } & \multirow{2}{*}{$\begin{array}{l}\text { Sensitivity } \\
\text { classification }\end{array}$} & \multicolumn{2}{|c|}{ Year 2006-2007 } & \multicolumn{2}{|c|}{ Year 2008-2009 } \\
\hline & & $\%(n)$ & $\mathrm{IC}_{50}, \mathrm{nM}$ & $\%(n)$ & $\mathrm{IC}_{50}, \mathrm{nM}$ \\
\hline \multirow[t]{3}{*}{ AS } & All & $100(56)$ & $2.0(1.5-2.4)$ & $100(63)$ & $2.0(1.5-2.5)$ \\
\hline & Sensitive & $60.7(34)$ & $1.4(1.3-1.6)$ & $58.7(37)$ & $1.4(1.1-1.8)$ \\
\hline & Declined sensitivity & $39.3(22)$ & $3.1(2.8-3.3)$ & $41.3(26)$ & $3.7(3.2-4.2)$ \\
\hline \multirow[t]{3}{*}{ MQ } & All & $100(56)$ & $30.4(18.0-42.7)$ & $100(63)$ & $28.8(16.7-41.0)$ \\
\hline & Sensitive & $42.9(24)$ & $13.8(11.3-16.3)$ & $41.3(26)$ & $16.2(13.2-19.2)$ \\
\hline & Resistant & $57.1(32)$ & $51.5(40.3-62.7)$ & $58.3(37)$ & $58.7(49.3-68.1)$ \\
\hline \multirow[t]{4}{*}{ CQ } & All & $100(56)$ & $69.9(62.8-77.1)$ & $100(63)$ & $72.3(65.4-79.2)$ \\
\hline & Sensitive & $1.8(1)$ & 9.6 & - & - \\
\hline & Moderate resistant & $76.8(43)$ & $65.9(59.9-72.0)$ & $69.8(44)$ & $66.6(62.3-70.8)$ \\
\hline & Highly resistant & $21.4(12)$ & $124.3(108.1-140.6)$ & $30.2(19)$ & $132.3(68.1-196.5)$ \\
\hline \multirow[t]{3}{*}{ QN } & All & $100(56)$ & $236.3(186.2-286.4)$ & $100(63)$ & $230.5(164.8-296.2)$ \\
\hline & Sensitive & $78.6(44)$ & $223.0(178.6-267.3)$ & $93.7(59)$ & $214.9(150.4-279.4)$ \\
\hline & Resistant & $21.4(12)$ & $648.9(606.1-691.6)$ & $6.3(4)^{* *}$ & $593.6(491.0-696.2)$ \\
\hline
\end{tabular}

Data presented as median $\mathrm{IC}_{50}(95 \% \mathrm{Cl})$ and percentage (number).

** Significant lower proportion than isolates collected from 2006-2007 ( $p=0.016$, Chi-square test).

(19/123), 13.8\% (17/123), 17.1\% (21/123), 0.8\% (1/123), $3.3 \%(4 / 123)$, and $0.8 \%(1 / 123)$, respectively. For the period 2006-2007, the isolates which carried one, two, three and four gene copies were found in $47.4 \%$ (27/57), $19.3 \%(11 / 57), 12.3 \%(7 / 57)$ and $21.1 \%(12 / 57)$, respectively. About 50\% (33/66), 12.1\% (8/66), 15.2\% (10/66), $13.6 \%$ (9/66), $1.5 \%(1 / 66), 6.1 \%(4 / 66)$, and $1.5 \%(1 / 66)$ of the isolates collected during 2007-2008 carried one, two, three, four, five, six and eight gene copies, respectively. There was no significant difference in the prevalence of $p f m d r 1$ gene copy in isolates collected during the two periods.

\section{Pfatp6 copy number}

All of the 67 isolates under the analysis from the two periods carried only one gene copy.

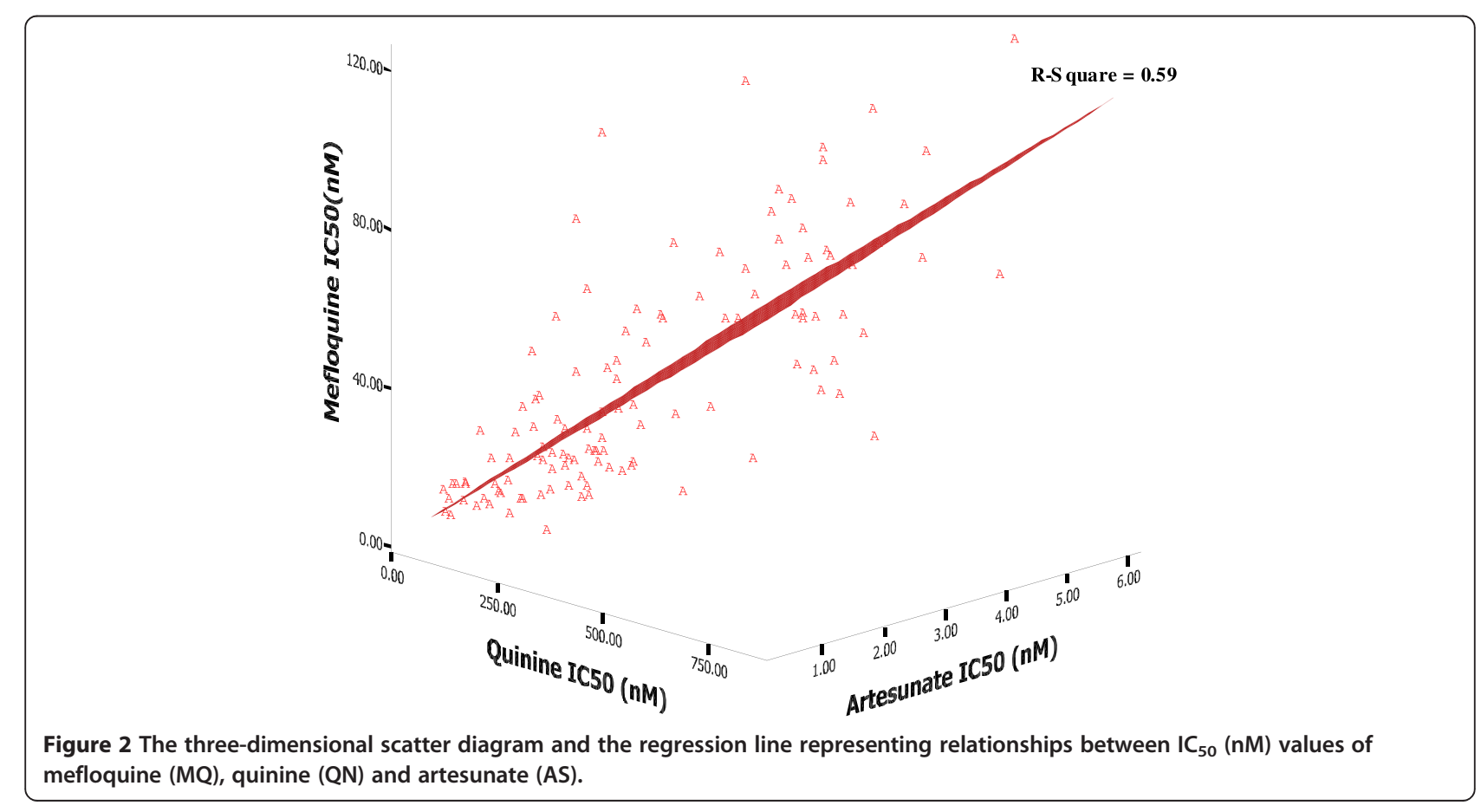


Association between polymorphisms of candidate molecular markers of anti-malarial drug resistance and in vitro sensitivity of Plasmodium falciparum isolates

The association between polymorphisms of candidate molecular markers of anti-malarial drug resistance and in vitro sensitivity to anti-malarial drugs was investigated in 119 matched-paired P. falciparum isolates (Figure 3).

\section{Pfatp6 mutation and pfatp6 copy number}

No significant association was observed between pfatp6 mutation including pfatp6 copy number and in vitro sensitivity of $P$. falciparum isolates to all drugs.

\section{Pfcrt mutation}

Significant association was observed between CQ resistance and pfcrt mutations at codons 76T, 220S, 271E, $326 \mathrm{~S}$, and 371I. Only one CQ sensitive isolate $\left(\mathrm{IC}_{50} 9.6\right.$ $\mathrm{nM}$ ) carried wild type genotype at codons 76, 220, 271, 326 , and $371(p=0.007)$.

\section{Pfmdr1 mutation}

The $\mathrm{IC}_{50}$ values of $\mathrm{MQ}$ and $\mathrm{QN}$ were significantly lower in the three (out of 117) isolates with $86 \mathrm{Y}$ mutation compared with those carried wild type (86 N) genotype [median (95\% CI) MQ IC 50 : 30.4 (21.9-38.8) vs 8.1 (3.49.1) $\mathrm{nM}, p=0.005$; median (95\% CI) QN IC 50 : 236.3 (195.7-276.9) vs 86.4 (32.2-119.1) nM, $p=0.015)$. The isolates carrying $1034 \mathrm{~S}$ had significantly lower QN $\mathrm{IC}_{50}$ than that carrying $1034 \mathrm{SC}\left[\mathrm{IC}_{50}(95 \% \mathrm{CI}) 134.3(46.3-\right.$ 222.6) vs 230.5(168.3-292.7) nM, $p=0.007]$.

\section{Pfmrp1 mutation}

CQ $\mathrm{IC}_{50}$ was significantly lower in isolates carrying $191 \mathrm{Y}$ compared with that carrying wild type $(\mathrm{H})$ genotype [median (95\% CI) IC $_{50} 81.4$ (58.2-104.7) and 69.9 (65.074.9) $\mathrm{nM}$, respectively; $p=0.008$ ]. The $\mathrm{QN} \mathrm{IC}_{50}$ was significantly lower in isolates carrying 1390I compared with that carrying wild type $1390 \mathrm{~F}$ genotype [median (95\% CI) QN IC 50 : 238.0 (191.0-285.1) vs 190.2 (100.7-279.8), $p=0.039$.

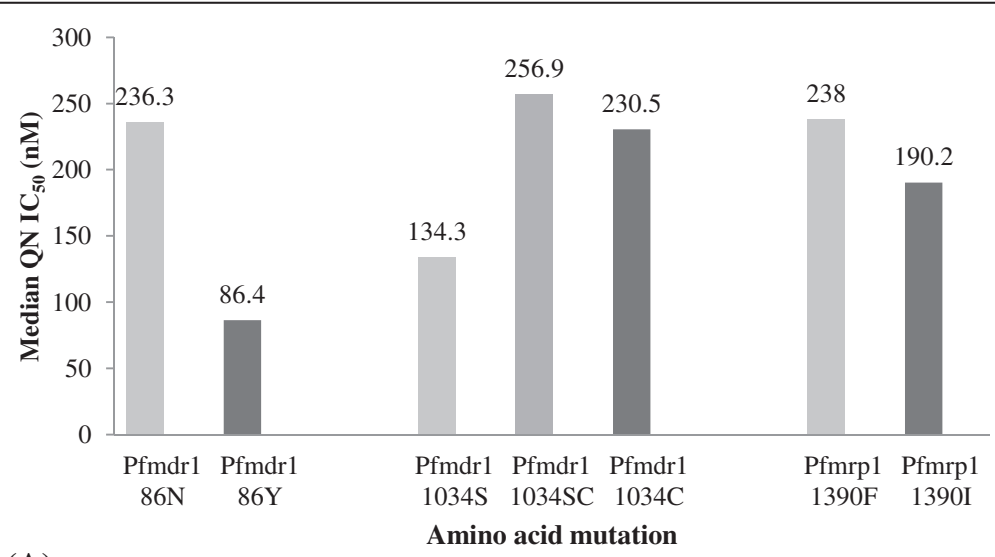

(A)

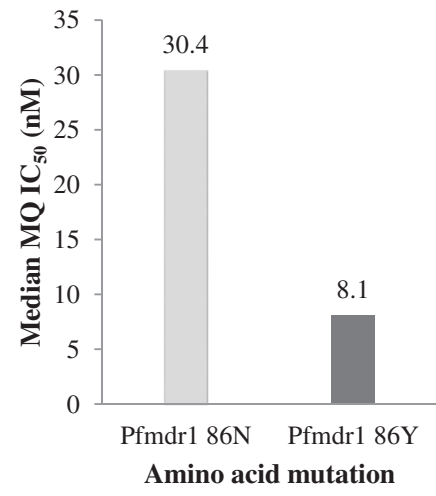

(B)

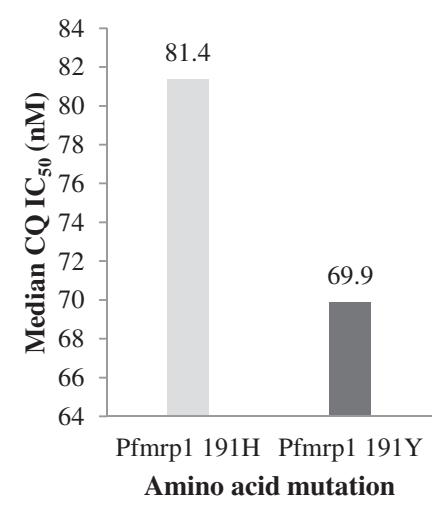

(C)

Figure 3 The relationship between median $\mathrm{IC}_{50}$ values of quinine (QN), mefloquine (MQ) and chloroquine (CQ) and the mutations of pfmdr1 and pfmrp1 gene in Plasmodium falciparum isolates. Association between (A) QN IC 50 and pfmdr1 N86Y $(p=0.015$, Mann-Whitney U test), S1034C ( $p=0.018$, Kruskal-Wallis test) and pfmrp1 F1390I mutation ( $p=0.039$, Mann-Whitney U test); (B) MQ IC 50 and pfmdr1 N86Y mutation ( $p=0.005$, Mann-Whitney $U$ test); and (C) CQ IC 50 and pfmrp $1 \mathrm{H} 191 \mathrm{Y}$ mutation ( $p=0.008$, Mann-Whitney $U$ test). 


\section{Pfmdr1 copy number}

A marked difference in $\mathrm{IC}_{50}$ values of $\mathrm{AS}, \mathrm{MQ}$ and $\mathrm{QN}$ was observed among isolates carrying one, two, three, and $\geq$ four gene copies [median $(95 \% \mathrm{CI}) \mathrm{AS} \mathrm{IC}_{50}: 1.6$ (1.3-1.9), 1.8 (1.1-2.5), 2.9 (2.1-3.7) and 3.1 (2.5-3.7) nM, $p<0.001$; MQ IC 50 : 19.2 (15.8-22.6), 37.8 (10.7-64.8), 55.3 (47.7-62.9) and 63.6 (49.2-78.0) $\mathrm{nM}, p<0.001$; and QN IC I0: 183.0 (139.9-226.4), 256.4 (83.7-249.1), 329.5 (206.6-425.5) and 420.0 (475.2-475.6) nM, respectively, $p<0.001]$. Significant positive correlation was found between the increased $p f m d r 1$ copy number and in vitro sensitivity of $P$. falciparum isolates to AS $(r=+0.47, p<$ $0.001)$, MQ $(r=+0.65, p<0.001)$, and QN $(r=+0.50, p<$ $0.001)$, while a significant negative correlation was found with CQ $(r=-0.19, p=0.038)$ (Figure 4).

\section{Discussion}

The present study investigated the relationship between $P$. falciparum gene polymorphisms (pfatp6, pfcrt, pfmdr1, and pfmrp1) and in vitro sensitivity of P. falciparum isolates to the ACT combination partners AS and
MQ, including CQ and QN in a multidrug-resistant area along the Thai-Myanmar border during the two periods (2006-2007 and 2008-2009). Results suggest a significant change in the prevalence and pattern of pfatp6, $p f m d r 1$ and $p f m r p 1$ gene polymorphisms with no change in the in vitro sensitivity profiles of the parasite during the two periods. Decline in sensitivity of $P$. falciparum to MQ was continuously reported during 1991-1994 when MQ monotherapy was employed in Thailand [27]. However, until a decade after the switch of first-line treatment to AS-MQ combination, high prevalence and intensity of MQ resistance was reported (32\%, 46\% and 58\% during 1998-2005 [28], 2007-2008 [29], and 20062009 (the current study), respectively). While evidence of artemisinin resistance was documented in Western Cambodia during the period 2006-2007 [30,31], sensitivity of $P$. falciparum isolates in this area to AS during the same period was generally considered satisfactory $[18,29,32,33]$. Subsequent reports on a decline in AS sensitivity [7,9] nevertheless, has created a major concern on the future use of AS in combination therapy.

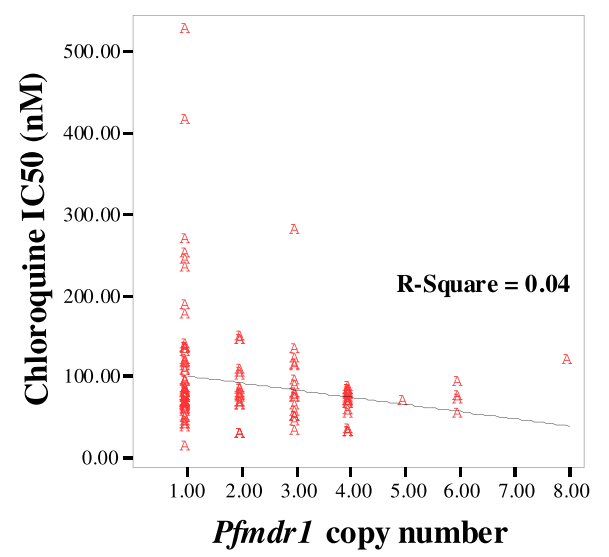

(A)

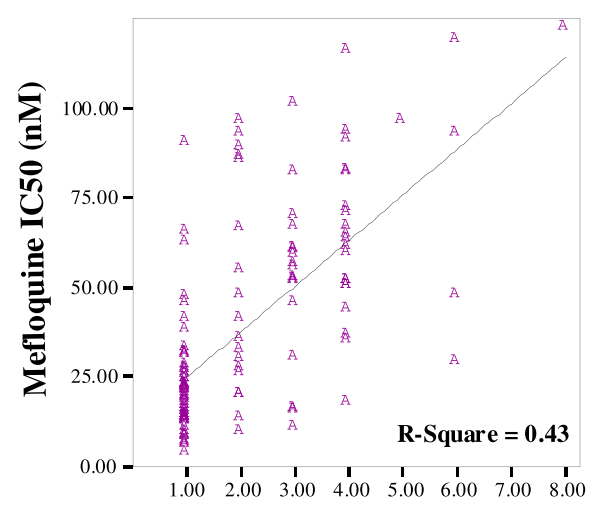

(C)

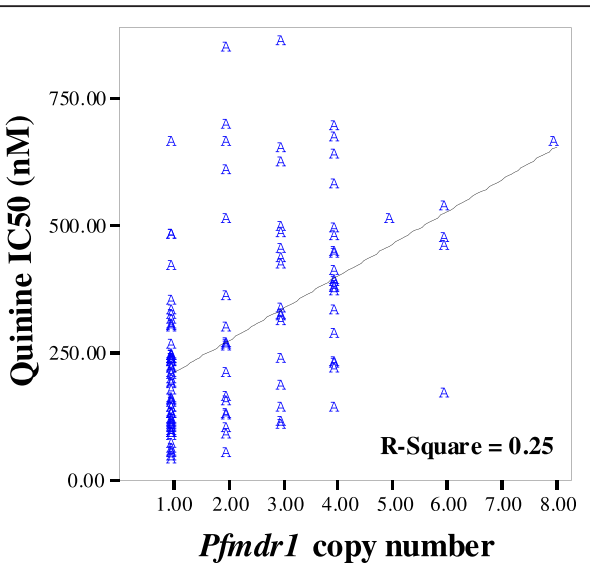

(B)

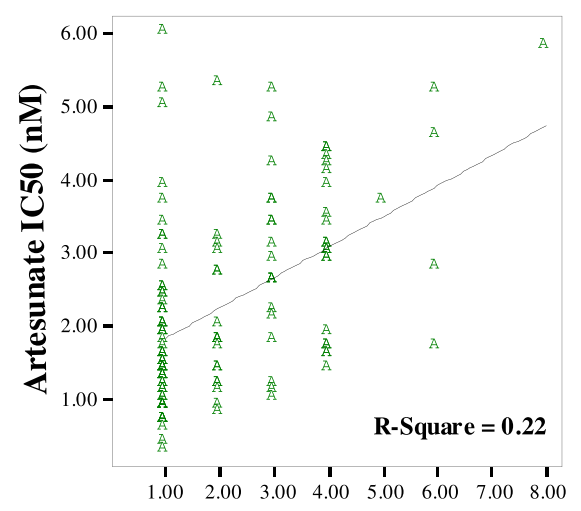

(D)

Pfindr1 copy number

Figure 4 Correlation between pfmdr1 copy number and in vitro sensitivity of Plasmodium falciparum isolates to (A) chloroquine (CQ), (B) quinine (QN), (C) mefloquine (MQ), and, (D) artesunate (AS). 
Without definite criteria for defining artemisinin resistance, the upper limit of $95 \% \mathrm{CI}$ of median $\mathrm{IC}_{50}$ value of AS in isolates collected from all patients $(2.3 \mathrm{nM})$ was used as a cut-off level of AS resistance in the present study. Based on this cut-off level, approximately $42 \%$ of the isolates were classified as declined sensitivity to AS. The prevalence of isolates with MQ resistance and declined sensitivity to AS observed in the present study were similar to that previously reported (58 vs 57.6\% and 42 vs 36.7\%, respectively) [34]. This cut-off criteria for defining AS resistance (the upper limit of 95\% CI of median $\mathrm{IC}_{50}$ value of $\mathrm{AS}$ ) was slightly lower in the current study $(2.3 \mathrm{nM})$ compared with the previous study $(2.8 \mathrm{nM})$ [34]. The sensitivity to $\mathrm{AS}\left(\mathrm{IC}_{50}: 2.0 \mathrm{vs}\right.$ $1.7 \mathrm{nM}$ ) and MQ (30.1 vs 34.0) were comparable with that reported in the isolates collected from Cambodia during the same period [35].

It was noted for the improvement of parasite sensitivity in this area to CQ and QN since the introduction of AS-MQ combination in Thailand in 1995. There was even one isolate that was sensitive to CQ. In 1991-1992 and 1994, the degree of CQ resistance in the country was high [median (95\% CI) IC $_{50} 193.2$ (148.24-251.85) and 157.0 (124.11-198.73) nM, respectively] [27], but was improved during the 1997, 1999 and 20042009 [median (95\% CI) IC 50157.0 (128.0-193.0), 120.5 (105.7-137.3) and 70.0 (10.0-183.0) nM, respectively] $[18,36,37]$. Molecular analysis in either laboratory or field $P$. falciparum isolates demonstrated the strong linkage between $C Q$ resistance and pfcrt gene mutations $[20,22,38]$. Susceptibility of the parasite to CQ was also shown in this study to link with pfmrp1 polymorphism, of which the 191Y mutation resulted in increased susceptibility of the parasite to CQ. For QN, a decline in parasite sensitivity to the drug was obviously observed during 1991-1992 and 1994 [mean (95\% CI) IC 50576.2 (460.51720.99) and 403.9 (330.50-493.54) nM, respectively], but was improved during 1997-2008 [18,36,37,39]. A total of 16 isolates were identified as QN resistance, 12 and four isolates collected during 2006-2007 and 2008-2009, respectively.

Pfmdr1 and pfmrp1 appear to be the key genes involved in resistance of $P$. falciparum to the commonly used anti-malarial drugs. The pfmdr1 $86 \mathrm{Y}$ mutation leads to increase in susceptibility of the parasite to MQ compared with wild type genotype $\left(\mathrm{IC}_{50}\right.$ of 8.1 and 30.4 $\mathrm{nM}$, respectively) as well as the structurally related antimalarial QN ( $\mathrm{IC}_{50}$ of 86.4 and $236.3 \mathrm{nM}$ ). The results showed low prevalence of $184 \mathrm{~F}$ allele in parasite isolates collected during the investigation period. The $184 \mathrm{~F}$ allele was reported to be associated with increased $\mathrm{IC}_{50}$ of MQ. High prevalence of $(\sim 86 \%)$ of the $184 \mathrm{~F}$ allele was reported in western Cambodia where the level of MQ resistance was significant. On the other hand, the prevalence of $184 \mathrm{~F}$ allele in eastern Cambodia was low $(\sim 32 \%)$, which was also correlated with the reduced level of MQ resistance in this region [40]. Molecular analysis in the current study revealed an obvious involvement of pfmdr1 and pfmrp1 genes with QN-resistant P. falciparum [13,14,21,41]. The pfmdr1 86Y and pfmrp1 1390I mutations resulted in an improvement of sensitivity of the parasite to QN compared with the wild type isolates [(86.4 vs $236.3 \mathrm{nM}$ ) and (190.2 vs $238.0 \mathrm{nM})$, respectively]. On the other hand, the mutation and heterozygous mutation of pfindr1 1034C resulted in the decreased susceptibility of the parasite to QN (median $\mathrm{IC}_{50}$ of 230.5, 256.9 and 190.3 $\mathrm{nM}$ for mutated, heterozygous mutated and wild type genotypes, respectively). Interestingly, the prevalence of pfmrp1 1390 (I) in parasite isolates collected during 2008-2009 was higher than that collected during 2006-2007.

With regard to the pfatp6 polymorphisms, there were no mutations found at codons 37, 639 and 769 in samples collected during 2006-2009. The mutation at codon 898 was found in isolates collected from 2008-2009. Although this residue is silent mutation, this observation may imply on the influence of anti-malarial drug pressure on the parasite during that period. The finding was in agreement with that reported by Jambou and colleges for the isolates in Asia including Thailand [11]. It is noted however that in vitro cultivation may cause the poor fitness of the mutant genotypes, which may explain the observation of almost absence of the mutation in pfatp6 gene in this study [42].

The current results support the role of $p f m d r 1$ amplification in modulating the degree of AS, MQ and QN susceptibility $[43,44]$ A trend of increasing number of gene copies and increasing $\mathrm{IC}_{50}$ values of $\mathrm{AS}, \mathrm{MQ}$ and $\mathrm{QN}$ was clearly observed. Approximately $51 \%$ of the isolates carried pfmdr1 copy number ranging from two to eight copies. The study conducted during 1995-2007, the period of which the clinical efficacy of AS-MQ combination was satisfactory, showed the increase in pfindrlcopy number from 30\% (12/40) in 1996 to $53 \%$ $(24 / 45)$ in 2006 [45]. Besides the high level of initial parasitaemia, prolongation of parasite clearance time and reduced in vitro parasite sensitivity to MQ, treatment failure following AS-MQ combination therapy was also associated with increased pfmdr1 copy number. Parasite isolates collected prior to treatment from patients with recrudescent response were found to carry higher number of $p f m d r 1$ copies compared to those with sensitive response (mean copies of 2.7 vs 1.9). In addition, isolates collected on the day of recrudescence carried higher number of gene copies than the corresponding day 0 samples (mean copies 3.5 vs 2.6) [35]. In a previous study, about $70 \%$ of isolates collected from patients with recrudescence response before AS-MQ treatment was shown to carry more than 1 pfmdr 1 copy 
number and increase in $p f m d r 1$ copy number was associated with reduced parasite sensitivity to AS, or resistant to $\mathrm{MQ}$, or both [34]. Although the artemisinin resistance has not been clearly defined in this study, results suggest that both the parasite (reduced in vitro sensitivity and increased pfmdr1 copy number) and host (pharmacokinetic variability) factors might contribute to artemisinin resistance $[9,46]$.

\section{Conclusions}

Based on results of the current observation on in vitro sensitivity and candidate molecular markers of resistance, it is concluded that high prevalence of MQ resistance still remained during the four years' observation period (2006-2009). In addition, sensitivity of the parasite to AS appeared to be declining. Pfmdr1 gene copy number is the key molecular marker of resistance of $P$. falciparum isolates in this area to AS-MQ combination therapy.

\section{Competing interests}

The authors declare that they have no competing interests.

\section{Authors' contributions}

$\mathrm{KN}$ was involved in providing the conception, design of the study and revised the manuscript critically for intellectual content and approved the final version of the manuscript. PP, PM and RW performed the investigation on the polymorphisms of pfatp6, pfcrt, pfmdr 1 and pfmrp 1 genes and in vitro sensitivity test. PP and WC performed data analysis and interpretation. PP drafted the manuscript. All authors read and approved the final manuscript.

\section{Acknowledgements}

The study was supported by The Commission on Higher Education, Ministry of Education of Thailand, the National Research University Project of Thailand (NRU), Office of Higher Education Commission, The Royal Golden Jubilee PhD Programme, Thailand Research Fund - Thammasat University Joint Fund and Graduated Student Grant to P. Phompradit, Thammasat University.

\section{Author details}

${ }^{1}$ Chulabhorn International College of Medicine, Thammasat University (Rangsit Campus), Patumthani 12121, Thailand. ${ }^{2}$ Thailand Centre of Excellence on Drug Discovery and Development, Thammasat University (Rangsit campus), Patumthani 12121, Thailand. ${ }^{3}$ Division of Haematology, Faculty of Medicine, Ramathibodi Hospital, Mahidol University, Bangkok 10400, Thailand.

Received: 27 September 2013 Accepted: 9 January 2014 Published: 15 January 2014

\section{References}

1. Verdrager J: Epidemiology of the emergence and spread of drugresistant falciparum malaria in South-East Asia and Australasia. J Trop Med Hyg 1986, 89:277-289.

2. Roper C, Pearce R, Nair S, Sharp B, Nosten F, Anderson T: Intercontinental spread of pyrimethamine-resistant malaria. Science 2004, 305:1124

3. Fontanet AL, Johnston DB, Walker AM, Rooney W, Thimasarn K, Sturchler D, Macdonald M, Hours M, Wirth DF: High prevalence of mefloquineresistant falciparum malaria in eastern Thailand. Bull World Health Organ 1993, 71:377-383.

4. Nosten F, Luxemburger C, ter Kuile FO, Woodrow C, Eh JP, Chongsuphajaisiddhi T, White NJ: Treatment of multidrug-resistant Plasmodium falciparum malaria with 3-day artesunate-mefloquine combination. J Infect Dis 1994, 170:971-977.

5. Nosten F, van Vugt M, Price $R$, Luxemburger $C$, Thway $K L$, Brockman A, McGready R, ter Kuile F, Looareesuwan S, White NJ: Effects of artesunate- mefloquine combination on incidence of Plasmodium falciparum malaria and mefloquine resistance in western Thailand: a prospective study. Lancet 2000, 356:297-302.

6. Noedl H, Se Y, Sriwichai S, Schaecher K, Teja-Isavadharm P, Smith B, Rutvisuttinunt W, Bethell D, Surasri S, Fukuda MM, Socheat D, Chan Thap L: Artemisinin resistance in Cambodia: a clinical trial designed to address an emerging problem in Southeast Asia. Clin Infect Dis 2010, 51:e82-e89.

7. Na-Bangchang K, Karbwang J: Emerging artemisinin resistance in the border areas of Thailand. Expert Rev Clin Pharmacol 2013, 6:307-322.

8. Congpuong K, Bualombai P, Banmairuroi V, Na-Bangchang K: Compliance with a three-day course of artesunate-mefloquine combination and baseline anti-malarial treatment in an area of Thailand with highly multidrug resistant falciparum malaria. Malar J 2010, 9:43.

9. Na-Bangchang K, Ruengweerayut R, Mahamad P, Ruengweerayut K, Chaijaroenkul W: Declining in efficacy of a three-day combination regimen of mefloquine-artesunate in a multi-drug resistance area along the Thai-Myanmar border. Malar J 2010, 9:273.

10. Sanchez C, Dave A, Stein W, Lanzer M: Transporters as mediators of drug resistance in Plasmodium falciparum. Int J Parasitol 2010, 40:1109-1118.

11. Jambou R, Legrand E, Niang M, Khim N, Lim P, Volney B, Ekala MT, Bouchier C, Esterre P, Fandeur T, Mercereau-Puijalon O: Resistance of Plasmodium falciparum field isolates to in-vitro artemether and point mutations of the SERCA-type PfATPase6. Lancet 2005, 366:1960-1963.

12. Dahlstrom S, Ferreira PE, Veiga MI, Sedighi N, Wiklund L, Martensson A, Farnert A, Sisowath C, Osorio L, Darban H, Andersson B, Kaneko A, Conseil G, Björkman A Gil JP: Plasmodium falciparum multidrug resistance protein 1 and artemisininbased combination therapy in Africa. J Infect Dis 2009, 200:1456-1464.

13. Raj DK, Mu J, Jiang H, Kabat J, Singh S, Sullivan M, Fay MP, McCutchan TF, Su XZ: Disruption of a Plasmodium falciparum multidrug resistanceassociated protein (PfMRP) alters its fitness and transport of antimalarial drugs and glutathione. J Biol Chem 2009, 284:7687-7696.

14. Veiga MI, Ferreira PE, Jornhagen L, Malmberg M, Kone A, Schmidt BA, Petzold M, Bjorkman A, Nosten F, Gil JP: Novel polymorphisms in Plasmodium falciparum $\mathrm{ABC}$ transporter genes are associated with major ACT antimalarial drug resistance. PLoS One 2011, 6:e20212.

15. Trager $W$, Jensen JB: Human malaria parasites in continuous culture. Science 1976, 193:673-675.

16. Bennett TN, Paguio M, Gligorijevic B, Seudieu C, Kosar AD, Davidson E, Roepe PD: Novel, rapid, and inexpensive cell-based quantification of antimalarial drug efficacy. Antimicrob Agents Chemother 2004, 48:1807-1810.

17. Smilkstein M, Sriwilaijaroen N, Kelly JX, Wilairat P, Riscoe M: Simple and inexpensive fluorescence-based technique for high-throughput antimalarial drug screening. Antimicrob Agents Chemother 2004, 48:1803-1806.

18. Phompradit P, Wisedpanichkij R, Muhamad P, Chaijaroenkul W, Na-Bangchang K: Molecular analysis of pfatp6 and pfmdr1 polymorphisms and their association with in vitro sensitivity in Plasmodium falciparum isolates from the Thai-Myanmar border. Acta Trop 2011, 120:130-135.

19. Wooden J, Kyes S, Sibley CH: PCR and strain identification in Plasmodium falciparum. Parasitol Today 1993, 9:303-305.

20. Fidock DA, Nomura T, Talley AK, Cooper RA, Dzekunov SM, Ferdig MT, Ursos LM, Sidhu AB, Naude B, Deitsch KW, Su XZ, Wootton JC, Roepe PD, Wellems TE: Mutations in the $P$. falciparum digestive vacuole transmembrane protein PfCRT and evidence for their role in chloroquine resistance. $\mathrm{Mo}$ Cell 2000, 6:861-871.

21. Duraisingh MT, Cowman AF: Contribution of the pfmdr1 gene to antimalarial drug-resistance. Acta Trop 2005, 94:181-190.

22. Duraisingh MT, Jones $P$, Sambou I, von Seidlein L, Pinder M, Warhurst DC: The tyrosine-86 allele of the pfmdr1 gene of Plasmodium falciparum is associated with increased sensitivity to the anti-malarials mefloquine and artemisinin. Mol Biochem Parasitol 2000, 108:13-23.

23. Ferreira ID, Martinelli A, Rodrigues LA, do Carmo EL, do Rosario VE, Povoa MM, Cravo P: Plasmodium falciparum from para state (Brazil) shows satisfactory in vitro response to artemisinin derivatives and absence of the S769N mutation in the SERCA-type PfATPase6. Trop Med Int Health 2008, 13:199-207.

24. Holmgren G, Gil JP, Ferreira PM, Veiga Ml, Obonyo CO, Bjorkman A: Amodiaquine resistant Plasmodium falciparum malaria in vivo is associated with selection of pfcrt $76 \mathrm{~T}$ and pfmdr1 $86 \mathrm{Y}$. Infect Genet Evol 2006, 6:309-314

25. Pirahmadi S, Zakeri S, Afsharpad M, Djadid ND: Mutation analysis in pfmdr1 and pfmrp1 as potential candidate genes for artemisinin 
resistance in Plasmodium falciparum clinical isolates 4years after implementation of artemisinin combination therapy in Iran. Infect Genet Evol 2013, 14:327-334

26. Ferreira I, do Rosário VE, Cravo P: Real-time quantitative PCR with SYBR Green I detection for estimating copy numbers of nine drug resistance candidate genes in Plasmodium falciparum. Malar J 2006, 5:1.

27. Wongsrichanalai C, Wimonwattrawatee T, Sookto P, Laoboonchai A, Heppner D, Kyle D, Wernsdorfer W: In vitro sensitivity of Plasmodium falciparum to artesunate in Thailand. Bull World Health Organ 1999, 77:392-398.

28. Chaijaroenkul W, Bangchang KN, Mungthin M, Ward SA: In vitro antimalarial drug susceptibility in Thai border areas from 1998-2003. Malar J 2005, 4:37.

29. Chaijaroenkul W, Wisedpanichkij R, Na-Bangchang K: Monitoring of in vitro susceptibilities and molecular markers of resistance of Plasmodium falciparum isolates from Thai-Myanmar border to chloroquine, quinine, mefloquine and artesunate. Acta Trop 2010, 113:190-194.

30. Dondorp A, Nosten F, Yi P, Das D, Phyo A, Tarning J, Lwin K, Ariey F, Hanpithakpong W, Lee S, Ringwald P: Artemisinin resistance in Plasmodium falciparum malaria. N Engl J Med 2009, 361:455-467.

31. Noedl H, Se Y, Schaecher K, Smith BL, Socheat D, Fukuda MM: Evidence of artemisinin-resistant malaria in western Cambodia. N Engl J Med 2008, 359:2619-2620.

32. Noedl H, Faiz MA, Yunus EB, Rahman MR, Hossain MA, Samad R, Miller RS, Pang LW, Wongsrichanalai C: Drug-resistant malaria in Bangladesh: an in vitro assessment. Am J Trop Med Hyg 2003, 68:140-142.

33. Woitsch B, Wernsdorfer G, Prajakwong S, Rojanawatsirivet C, Kollaritsch $H_{\text {, }}$ Wernsdorfer WH: Comparative study of the in vitro sensitivity of Plasmodium falciparum to artemisinin in two border areas of Thailand. Wiener klinische Wochenschrift 2004, 116(Suppl 4):35-40.

34. Na-Bangchang K, Muhamad P, Ruaengweerayut R, Chaijaroenkul W, Karbwang J: Identification of resistance of Plasmodium falciparum to artesunate-mefloquine combination in an area along the Thai-Myanmar border: integration of clinico-parasitological response, systemic drug exposure, and in vitro parasite sensitivity. Malar J 2013, 12:263.

35. Rogers WO, Sem R, Tero T, Chim P, Lim P, Muth S, Socheat D, Ariey F, Wongsrichanalai C: Failure of artesunate-mefloquine combination therapy for uncomplicated Plasmodium falciparum malaria in southern Cambodia. Malar J 2009, 8:10.

36. Wongsrichanalai C, Lin K, Pang L, Faiz M, Noedl H, Wimonwattrawatee T, Laoboonchai A, Kawamoto F: In vitro susceptibility of Plasmodium falciparum isolates from Myanmar to antimalarial drugs. Am J Trop Med Hyg 2001, 65:450-455.

37. Attlmayr B, Kollaritsch $H$, Wernsdorfer W, Miller R, Sirichaisinthop J, Noedl H: Drug sensitivity of Plasmodium falciparum along the Thai-Myanmar border using the new field-deployable HRP2 in vitro assay. Wien Klin Wochenschr 2005, 117:35-38.

38. Djimde A, Doumbo OK, Cortese JF, Kayentao K, Doumbo S, Diourte Y, Dicko A, Su XZ, Nomura T, Fidock DA, Wellems TE, Plowe CV: A molecular marker for chloroquine-resistant falciparum malaria. N Engl J Med 2001, 344:257-263.

39. Lim P, Wongsrichanalai C, Chim P, Khim N, Kim S, Chy S, Sem R, Nhem S, Yi $P$, Duong $S$, et al: Decreased in vitro susceptibility of Plasmodium falciparum isolates to artesunate, mefloquine, chloroquine, and quinine in Cambodia from 2001 to 2007. Antimicrob Agents Chemother 2010, 54:2135-2142.

40. Vinayak S, Alam MT, Sem R, Shah NK, Susanti Al, Lim P, Muth S, Maguire JD, Rogers WO, Fandeur T, Barnwell JW, Escalante AA, Wongsrichanalai C, Ariey F, Meshnick SR, Udhayakumar V: Multiple genetic backgrounds of the amplified Plasmodium falciparum multidrug resistance ( $p f m d r 1)$ gene and selective sweep of $184 \mathrm{~F}$ mutation in Cambodia. J Infect Dis 2010, 201:1551-1560.

41. Sidhu AB, Valderramos SG, Fidock DA: pfmdr1 mutations contribute to quinine resistance and enhance mefloquine and artemisinin sensitivity in Plasmodium falciparum. Mol Microbiol 2005, 57:913-926.

42. Legrand E, Volney B, Meynard JB, Mercereau-Puijalon O, Esterre P: In vitro monitoring of Plasmodium falciparum drug resistance in French Guiana: a synopsis of continuous assessment from 1994 to 2005. Antimicrob Agents Chemother 2008, 52:288-298.

43. Price RN, Cassar C, Brockman A, Duraisingh M, van Vugt M, White NJ, Nosten F, Krishna S: The pfmdr1 gene is associated with a multidrug resistant phenotype in Plasmodium falciparum from the western border of Thailand. Antimicrob Agents Chemother 1999, 43:2943-2949.
44. Price RN, Uhlemann AC, Brockman A, MCGready R, Ashley E, Phaipun L, Patel R, Laing K, Looareesuwan S, White NJ, Nosten F, Krishna S: Mefloquine resistance in Plasmodium falciparum and increased pfmdr1 gene copy number. Lancet 2004, 364:438-447.

45. Carrara VI, Zwang J, Ashley EA, Price RN, Stepniewska K, Barends M, Brockman A, Anderson T, McGready R, Phaiphun L, Proux S, van Vugt M, Hutagalung R, Lwin KM, Phyo AP, Preechapornkul P, Imwong M, Pukrittayakamee S, Singhasivanon P, White NJ, Nosten F: Changes in the treatment responses to artesunate-mefloquine on the northwestern border of Thailand during 13 years of continuous deployment. PLOS One 2009, 4:e4551.

46. Krishna S, Kremsner PG: Antidogmatic approaches to artemisinin resistance: reappraisal as treatment failure with artemisinin combination therapy. Trends Parasitol 2013, 29:313-317.

doi:10.1186/1475-2875-13-23

Cite this article as: Phompradit et al:: Four years' monitoring of in vitro sensitivity and candidate molecular markers of resistance of Plasmodium falciparum to artesunate-mefloquine combination in the Thai-Myanmar border. Malaria Journal 2014 13:23.

\section{Submit your next manuscript to BioMed Central and take full advantage of:}

- Convenient online submission

- Thorough peer review

- No space constraints or color figure charges

- Immediate publication on acceptance

- Inclusion in PubMed, CAS, Scopus and Google Scholar

- Research which is freely available for redistribution

Submit your manuscript at www.biomedcentral.com/submit
C) Biomed Central 